\title{
The Relationship of Chronic Spontaneous Urticaria with Anxiety and Depression in Children
}

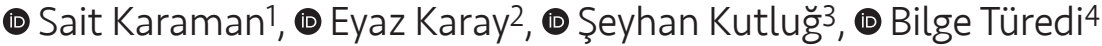 \\ 1Diyarbakır Children's Hospital, Clinic of Pediatric Allergy, Diyarbakır, Turkey \\ 2Diyarbakır Children's Hospital, Clinic of Child Psychiatry, Diyarbakır, Turkey \\ ${ }^{3}$ Batman Gynecology and Children Hospital, Clinic of Pediatric Allergy, Batman, Turkey \\ ${ }^{4}$ Diyarbakır Children's Hospital, Clinic of Pediatric Surgery, Diyarbakır, Turkey
}

\begin{abstract}
Aim: Chronic spontaneous urticaria (CSU) is characterized by urticaria recurring almost every day and lasting more than six weeks, with either known or unknown etiology. It may lead to various psychiatric disorders. Our aim is to determine the relationship of CSU with depression and anxiety in children.

Materials and Methods: Children younger than 18 years of age who were followed by the Pediatric Immunology and Allergy Clinic of Diyarbakır Children's Hospital with diagnosis of CSU were included in the study. A control group matched in terms of age and sex was formed. Both patient and control groups were evaluated by pediatric psychiatrics with regards to anxiety and depression. Prior to psychiatrics evaluation, Beck's anxiety and depression scales were applied to the children aged 12 years or above. Patient and control groups were compared for anxiety and depression disease and symptom scores.

Results: The study included 63 patients, 32 of whom were aged 12 years or above (12+ patients), and 82 controls, 32 of whom were aged 12 years or above (12+ controls). In the patient group, both anxiety and depression disorders were significantly more frequent. Similarly, anxiety and depression symptom scores were significantly higher in the 12+ patient group. This increase was found to show positive correlation with age and disease duration $(p<0.05)$. There were no significant differences between patients with and without autoimmunity regarding anxiety and depression disorder ( $p>0.05)$.
\end{abstract}

Conclusion: In children, CSU leads to anxiety and depression. This condition increases with age and disease duration.

Keywords: Allergy, anxiety, children, depression, urticaria

\section{Introduction}

Chronic urticaria is defined as the daily or almost daily occurrence of recurrent, transitory, and itchy wheals with or without accompanying angioedema for a period of six weeks or longer (1). Chronic spontaneous urticaria (CSU) is a type of chronic urticaria distinct from physical urticaria, with either known (e.g., autoantibodies) or unknown etiology (2). Most pediatric cases with chronic urticaria are reported to be spontaneous ( $55.9 \%$ of cases) (3). The point prevalence of CSU has been estimated at $0.1 \%$ to $0.3 \%$ for children (4). The development of various psychological disturbances in the case of chronic urticaria has been reported in previous studies. Depression and anxiety were the most common psychiatric diagnoses found in CSU patients; however, most of these studies were conducted on adult patients. A limited number of studies exist in the literature on this subject concerning children (5).

\section{Address for Correspondence}

Sait Karaman MD, Diyarbakır Children's Hospital, Clinic of Pediatric Allergy, Diyarbakır, Turkey Phone: +902362292600 E-mail: saitkaraman73@gmail.com ORCID: orcid.org/0000-0002-5109-2780 Received: 10.07.2019 Accepted: 29.08.2019

${ }^{\circ}$ Copyright 2020 by Ege University Faculty of Medicine, Department of Pediatrics and Ege Children's Foundation The Journal of Pediatric Research, published by Galenos Publishing House. 
In this study, we wanted to investigate the following hypotheses: Children with CSU show higher depression and anxiety compared to healthy controls. As the duration of illness increases, more anxiety and depression develop. Furthermore, children with autoimmunity tend to anxiety and depression more than children without autoimmunity.

\section{Materials and Methods}

\section{Subjects}

The study included 63 patients with the diagnosis of CSU who were followed by the Pediatric Immunology and Allergy Clinic of Diyarbakır Children's Hospital and who met the study inclusion criteria. This study was conducted in accordance with the guidelines of the Ethics Committee of the University of Health Sciences, Diyarbakır Gazi Yasargil Training and Research Hospital (decision dated December $14^{\text {th }}, 2018$, protocol number 2018/187, decision approval 2018/14-12). After informing the patients and their parents about the purpose and procedures of the study, written consent was obtained.

The inclusion criteria were as follows: (I) having a diagnosis of CSU as defined below; (II) being younger than 18 years of age; and (III) being able to sufficiently read, write, and comprehend the Turkish language for children aged 12 years or above. The exclusion criteria were: (I) having cognitive impairment due to psychotic illness or mental retardation; (II) receiving psychiatric treatment; (III) having an additional chronic illness; and (IV) having received corticosteroid medication within the previous 4 weeks.

Thirty-two healthy children (with no history of urticaria or other skin diseases) from a local school were included in the study as the control group for the twelve years and older age group (12+ controls). Fifty randomly selected patients younger than 12 years old who were admitted to the general pediatrics outpatient clinic of our hospital (with no history of urticaria or other skin diseases) were included as the control group. They were matched in age and gender with the study group. The same exclusion criteria as those of the study group were applied to the controls.

\section{Diagnosis of Chronic Spontaneous Urticaria}

The medical history was recorded and a physical examination was performed. Skin prick tests with inhalant and food allergens and provocation tests for physical urticaria were performed to diagnose physical urticaria. To investigate other causes of chronic spontaneous urticaria, patients underwent additional laboratory examinations including the following: (I) complete blood count, erythrocyte sedimentation rate, blood chemistry, liver function tests, serum levels of complement 4, free thyroxine, thyroid stimulating hormone, total serum IgE; (II) an autoimmune panel (antinuclear antibody, antithyroid peroxidase antibodies, antithyroglobulin antibodies); (III) an infection panel (hepatitis surface antigen, antibody titers for hepatitis $B$ and $C$ viruses, urine analysis and culture, Helicobacter pylori IgG antibodies, microscopic investigation of stool for parasite ova).

\section{Study Design}

The demographic properties of the patients and controls were recorded after interviewing the parents. Those patients and controls aged younger than 12 years were accompanied by their parents during their evaluation by a pediatric psychiatrist. Patients and controls aged 12 years or above were initially given Beck's anxiety inventory (BAI) and Beck's depression inventory (BDI). All patients were then evaluated by a pediatric psychiatrist, whereas in the control group, only those with a BAI score $>9$ and a $\mathrm{BDI}$ score $>13$ were invited to the clinic and evaluated by pediatric psychiatrist. Control cases with BAI and BDI scores below the aforementioned thresholds were presumed not to have anxiety or depression disorder. Patient and control groups were compared for anxiety and depression disease and symptom scores. Furthermore, those children with autoimmunity and without autoimmunity were compared for anxiety and depression disease.

\section{Scales}

The levels of depression and anxiety were assessed with the BDI (6) and the BAI (7). The reliability and validity of the Turkish versions of these instruments have been examined previously $(8,9)$. Diagnoses of depression and anxiety were based on the Diagnostic and Statistical Manual of Mental Disorders, Fifth Edition diagnostic criteria (10). BDI is a selfrating scale consisting of 21 items of depression. Each item has scores ranging from 0 to 3 on this scale. BAl is self-rating scale used to determine the level of anxiety in subjects. Similar to BDI, it has 21 items scored from 0 to 3 . The levels of anxiety according to BAI score are as follows: 0-9 points: minimal; $10-16$ points: mild; $17-29$ points: moderate; 30 and above: severe anxiety. The levels of depression according to BDI score are as follows: 0-13 points: minimal; 14-19 points: mild; $20-28$ points: moderate; 29 and above: severe depression $(6,7)$.

\section{Statistical Analysis}

IBM SPSS version 22.0 (Armonk, New York, United States) was used for all statistical analyses. The Kolmogorov- 
Smirnov test was used to test the normality of variables. Parametric methods were used for analysis of variables with a normal distribution, whereas non-parametric methods were used for analysis of variables that were not normally distributed. The Pearson's chi-square and linearby-linear association tests were used with an exact test for the comparison of categorical data. The categorical data are expressed as a percentage of the number ( $n$ ) of children evaluated. The level of significance for the analyses was $p<0.05$. Correlation of variables was analyzed with Spearman's rho test.

\section{Results}

The study included 63 patients, 33 of whom (52.3\%) were male, and 82 control cases, 45 of whom (54\%) were male. Thirteen of the 32 patients (40.6\%) aged 12 or above (12+ patients) were male, while 17 of 21 control cases (53.1\%) aged 12 or above $(12+$ controls) were male. The mean age was $11.5 \pm 3.9$ years in the patient group and $10.5 \pm 4.2$ years in the control group. The mean age of $12+$ patient group was $14.7 \pm 2.0$ years, and the mean age of the $12+$ control group was $15.3 \pm 1.8$ years. No significant differences were found between the patient and control groups regarding age and gender distribution ( $p>0.05$ ). Autoantibodies were detected in a total of 15 patients $(23.8 \%)$, with 8 being in the $12+$ patient group (Table I). In the patient group, BDI score and BAI score were at the minimal level in 20 (66.6\%) and $12(40 \%)$ patients, respectively, whereas in the control group, $\mathrm{BDI}$ score and BAI score were at the minimal level in $29(90.6 \%)$ and $28(87.5 \%)$ cases, respectively (Table II). In the patient group, 17 (26.9\%) patients had anxiety and $8(12.6 \%)$ patients had depression, whereas in the control group, three (3.6\%) cases had anxiety and none had depression. Both anxiety and depression were significantly more frequent in the patient group $(p<0.05)$. The mean BAI score was $16.2 \pm 12.5$ in the $12+$ patient group and $3.5 \pm 2.5$ in the $12+$ control group. The mean BDI score was $12.0 \pm 9.8$ in the patient group and $2.4 \pm 4.2$ in the control group. Both BAI score and BDI score were higher in the patient group $(p<0.05)$ (Table III). When patients were stratified according to autoimmunity status, no significant difference was found regarding anxiety and depression rates. Similarly, the mean BAI score and the mean BDI score of the $12+$ patient group were $10.0 \pm 7.4$ and $9.1 \pm 6.9$, respectively, for those having autoimmunity, and $18.0 \pm 14.1$ and $12.0 \pm 11.7$, respectively, for those without autoimmunity. BAI and BDI scores did not show significant differences when patients were stratified according to autoimmunity ( $p>0.05$ ) (Table IV). Disease duration and age showed positive correlation with both anxiety and depression rates as well as with BDI and BAI scores $(p<0.05)$.

Table II. Beck's depression inventory and Beck's anxiety inventory scores of individuals aged 12 years and older in patient and control groups

\begin{tabular}{|c|c|c|}
\hline & $\begin{array}{l}\text { Patient group, } \\
\mathrm{n}=32\end{array}$ & $\begin{array}{l}\text { Control group, } \\
\mathrm{n}=32\end{array}$ \\
\hline $\begin{array}{l}\text { BDI score } \\
\text { Minimal (0-13), n (\%) }\end{array}$ & $21(65.6)$ & $29(90.6)$ \\
\hline Mild (14-19), n (\%) & $5(15.6)$ & $4(9.3)$ \\
\hline Moderate (20-28), n (\%) & $3(9.3)$ & - \\
\hline Severe ( $\geq 29), \mathrm{n}(\%)$ & $3(9.3)$ & - \\
\hline $\begin{array}{l}\text { BAI score } \\
\text { Minimal (0-9), n (\%) }\end{array}$ & $12(37.5)$ & $28(87.5)$ \\
\hline Mild (10-16), n (\%) & $7(21.8)$ & $4(12.5)$ \\
\hline Moderate (17-29), n (\%) & $9(28.1)$ & - \\
\hline Severe ( $\geq 30), n(\%)$ & $4(12.5)$ & - \\
\hline
\end{tabular}

Table I. Demographic characteristics of patient and control groups

\begin{tabular}{|l|l|l|l|}
\hline & Patient group, $\mathbf{n = 6 3}$ & Control group, $\mathbf{n = 8 2}$ & $\mathbf{p}$ \\
\hline Gender (male), $\mathbf{n}(\%)$ & $33(52.3)$ & $45(54)$ & 0.335 \\
\hline Age, years* & $11.5 \pm 3.9$ & $10.5 \pm 4.2$ & 0.238 \\
\hline Disease duration, month* & $9.8 \pm 9.4$ & - & - \\
\hline Autoimmunity, $\mathbf{n}(\%)$ & $15(23.8)$ & - & \\
\hline & $12+$ Patient group, $\mathrm{n}=32$ & $12+$ Control group, $\mathrm{n}=32$ \\
\hline Gender (male), $\mathbf{n}(\%)$ & $13(40.6)$ & $17(53.1)$ & - \\
\hline Age, years* & $14.7 \pm 2.0$ & $15.3 \pm 1.8$ & 0.316 \\
\hline Disease duration, month* & $10.8 \pm 11.1$ & - & 0.418 \\
\hline Autoimmunity, $\mathbf{n}$ (\%) & $8(25)$ & - & - \\
\hline *: Mean \pm Standard deviation, n: Number & & & - \\
\hline
\end{tabular}


Table III. Comparison of rates and levels of anxiety and depression across patient and control groups according to age groups

\begin{tabular}{|l|l|l|l|}
\hline & $\begin{array}{l}\text { Patient } \\
\text { group, } \\
\mathbf{n = 6 3}\end{array}$ & $\begin{array}{l}\text { Control } \\
\text { group, } \\
\mathbf{n = 8 2}\end{array}$ & $\mathbf{p}$ \\
\hline Anxiety disorder, $\mathbf{n}(\%)$ & $17(26.9)$ & $3(3.6)$ & $\mathbf{0 . 0 0 0}$ \\
\hline $\begin{array}{l}\text { Depression disorder, } \mathbf{n} \\
(\%)\end{array}$ & $8(12.6)$ & $*$ & $\mathbf{0 . 0 0 1}$ \\
\hline & $\begin{array}{l}\text { 12+ Patient } \\
\text { group, } \mathrm{n}=32\end{array}$ & $\begin{array}{l}12+\text { Control } \\
\text { group, } \mathrm{n}=32\end{array}$ & \\
\hline Anxiety score** & $16.2 \pm 12.5$ & $3.5 \pm 2.5$ & $\mathbf{0 . 0 0 0}$ \\
\hline Depression score** & $12.0 \pm 9.8$ & $2.4 \pm 4.2$ & $\mathbf{0 . 0 0 1}$ \\
\hline *: No depression disorder, **: Mean \pm Standard deviation, n: Number \\
\hline
\end{tabular}

Table IV. Comparison of rates of anxiety and depression and symptom scores across autoimmune and non-autoimmune groups of patients with chronic spontaneous urticaria

\begin{tabular}{|l|l|l|l|}
\hline & $\begin{array}{l}\text { Autoimmune } \\
\text { group, } \mathbf{n = 1 5}\end{array}$ & $\begin{array}{l}\text { Non-autoimmune } \\
\text { group, } \mathbf{n = 4 8}\end{array}$ & $\mathbf{p}$ \\
\hline $\begin{array}{l}\text { Depression, } \\
\mathbf{n}(\%)\end{array}$ & $2(13.3)$ & $3(6.2)$ & 0.793 \\
\hline $\begin{array}{l}\text { Anxiety, } \\
\mathbf{n}(\%)\end{array}$ & $2(13.3)$ & $12(25)$ & 0.304 \\
\hline & $\begin{array}{l}12+\text { Autoimmune } \\
\text { group, } \mathrm{n}=8\end{array}$ & $\begin{array}{l}12+\text { Non- } \\
\text { autoimmune group, } \\
\mathrm{n}=24\end{array}$ & \\
\hline BDI score* & $9.1 \pm 6.9$ & $12.0 \pm 11.1$ & 0.419 \\
\hline BAI score* & $10.0 \pm 7.4$ & $18.1 \pm 14.1$ & 0.138 \\
\hline
\end{tabular}

BDI: Beck's depression inventory, BAI: Beck's anxiety inventory, *: Mean \pm Standard deviation, n: Number

\section{Discussion}

Although patients with CSU frequently have psychiatric comorbidities (11), the relationship between these two conditions is still not fully understood (12). In the literature, studies concerning psychiatric comorbidities in patients with CSU are mostly limited to the adult population (13). Studies examining this relationship during childhood are limited in number. The results of the present study show increased rates of anxiety and depression among children with CSU.

Studies have shown that the level of anxiety is frequently severe in the adult patient population with CSU (14). Barbosa et al. found an increased prevalence of anxiety among adult patients with CSU and reported that $47.3 \%$ had severe anxiety symptoms (15). Hergüner et al. (16) examined 27 pediatric patients with CSU and found higher levels of anxiety among patients compared to controls. Consistent with the literature, we found increased anxiety levels in children with CSU, with the majority having a mild-moderate level of anxiety. In addition, we found an increased rate of anxiety among patients with CSU.

Studies that were mostly conducted with the adult patient population showed that the level of depression was higher among patients with CSU, with most of them having severe depression (14). Engin et al. (17) evaluated 73 adult CSU patients and 34 control cases using BDI and found higher levels of depression among patients compared to controls. Similarly, Tat et al. (18) compared 50 adult CSU patients and 60 control cases and reported higher levels of depression in the patient group. In their study, Hergüner et al. (16) found a higher level of depression among children with CSU compared to control cases. Consistent with the literature, we found higher levels of depression among children with CSU, with the majority of this increase in the mild-moderate levels. Additionally, we also found an increased rate of depression among patients with CSU.

Studies have shown an increased level of depression with increasing age in the general population (19). Hergüner et al. (16) reported a positive correlation of disease duration and age with anxiety and Depression scores. On the other hand, Tat et al. (18) and Engin et al. (17) did not find a correlation between disease duration or age with Anxiety and Depression scores. In our study, we found a positive correlation of age with both anxiety and Depression scores and also with anxiety and depression rates. Additionally, we observed a positive correlation of disease duration with both anxiety and depression rates and Symptom scores.

In their study of 168 adult patients, Weller et al. (20) compared anxiety and Depression scores between patients who had positive and negative reactions to an autologous serum skin test and found lower anxiety and depression scores and lower rate of psychiatric comorbidities among autoreactive cases. In contrast, we did not find significant differences between patients with and without autoimmunity regarding anxiety and depression scores. In addition, the rates of anxiety and depression were similar between these two groups. The reason why we had a different result may be attributed to the fact that we used a different method to detect autoimmunity and because we had a low number of cases with autoimmunity due to the fact that autoimmunity is more prevalent among adult patients. We believe larger-scale studies are necessary in this regard.

\section{Study Limitations}

One limitation of this study was the number of our cases, which was not sufficient to evaluate the role of 
autoimmune etiology in psychiatric comorbidities in children with CSU. Another limitation was that our patients were receiving antihistaminic medications for treatment of CSU. We do not know whether this has any effect on anxiety and depression. We believe these limitations do not alter the reliability of our results.

\section{Conclusion}

The results of the present study demonstrated increased rates of anxiety and depression in children with CSU. Moreover, this increase was found to correlate with increasing age and disease duration. To our knowledge, this is the first study in the literature in which the diagnosis of anxiety and depression in children with CSU was made by a pediatric psychiatrist using survey results. We also found in this study that children who had autoimmunity as the presumed etiological factor for CSU did not differ from patients without autoimmunity in terms of anxiety and depression levels. This is also the first study in the literature evaluating the relationship between autoimmunity in children with CSU and anxiety and depression.

\section{Ethics}

Ethics Committee Approval: This study was conducted in accordance with the guidelines of the Ethics Committee of the University of Health Sciences, Diyarbakır Gazi Yasargil Training and Research Hospital (decision dated December $14^{\text {th }}, 2018$, protocol number $2018 / 187$, decision approval 2018/14-12).

Informed Consent: Written consent was obtained.

Peer-review: Enternally peer-reviewed.

\section{Authorship Contributions}

Medical Practices: S.K., E.K., Ş.K., B.T. Concept: S.K., E.K., S..K., B.T., Design: S.K., E.K., S..K., B.T., Data Collection or Processing: S.K., E.K., S..K., B.T., Analysis or Interpretation: S.K., E.K., Ş.K., B.T., Literature Search: S.K., E.K., Ş.K., B.T., Writing: S.K., E.K., S..K., B.T.

Conflict of Interest: The authors have no conflict of interest to declare.

Financial Disclosure: The authors declared that this study received no financial support.

\section{References}

1. Zuberbier T, Aberer W, Asero R, et al ; Endorsed by the following societies: AAAAI, AAD, AAIITO, ACAAI, AEDV, APAAACI, ASBAI, ASCIA, BAD, BSACI, CDA, CMICA, CSACl, DDG, DDS, DGAKI, DSA, DST, EAACI, EIAS, EDF, EMBRN, ESCD, GA²LEN, IAACI, IADVL, JDA NVVA, MSAI, ÖGDV, PSA, RAACI, SBD, SFD, SGAI, SCDV, SIAAIC SIDeMaST, SPDV, TSD, UNBB, UNEV and WAO. The EAACI/
GA²LEN/EDF/WAO guideline for the definition, classification, diagnosis and management of urticaria. Allergy 2018;73:1393-1414.

2. Zuberbier T, Bernstein JA. A Comparison of the United States and International Perspective on Chronic Urticaria Guidelines. I Allergy Clin Immunol Pract 2018;6:1144-51.

3. Caffarelli C, Cuomo B, Cardinale F, et al. Aetiological factors associated with chronic urticaria in children: a systematic review. Acta Derm Venereol 2013;93:268-72.

4. Ferriani MP, Silva MF, Pereira RM, et al. Chronic Spontaneous Urticaria: A Survey of 852 Cases of Childhood-Onset Systemic Lupus Erythematosus. Int Arch Allergy Immunol 2015;67:186-92.

5. Zuberbier $T$, Balke $M$, Worm $M$, Edenharter $G$, Maurer $M$. Epidemiology of urticaria: a representative cross-sectional population survey. Clin Exp Dermatol 2010;35:869-73.

6. Beck AT, Ward CH, Mehdelson M, Mosk J, Erbaugh J. An inventory for measuring depression. Arch General Psychiatry 1961;4:561-71.

7. Beck AT, Epstein N, Brown G, Steer RA. An inventory for measuring clinical anxiety: psychometric properties. I Consult Clin Psychol 1988;56:893-7.

8. Hisli N. The validity and reliability of Beck Depression Inventory in University students. J Psychol 1989;7:2-13.

9. Ulusoy $\mathrm{M}$, Sahin $\mathrm{NH}$, Erkmen $\mathrm{H}$. Turkish version of the beck anxiety inventory: psychometric properties. I Cogn Psychother 1998;12:163-72.

10. American Psychiatric Association. Diagnostic and Statistical Manual of Mental Disorders, Fifth Edition (DSM-5), American Psychiatric Association, Arlington, VA 2013.

11. Staubach P, Eckhardt-Henn A, Dechene M, et al. Quality of life in patients with chronic urticaria is differentially impaired and determined by psychiatric comorbidity. $\mathrm{Br}$ / Dermatol 2006; 154:294-8.

12. Maurer M, Weller K, Bindslev-Jensen C, et al. Unmet clinical needs in chronic spontaneous urticaria. A GA(2) LEN task force report. Allergy 2011;66:317-30.

13. Uguz F, Engin B, Yilmaz E. Axis I and Axis II diagnoses in patients with chronic idiopathic urticaria. J Psychosom Res 2008;64:225-9.

14. Weldon D. Quality of life in patients with urticaria. Allergy \& Asthma Proceedings 2006;27:96-9.

15. Barbosa F, Freitas I, Barbosa A. Chronic idiopathic urticaria and anxiety symptoms. / Health Psychol 2011;16:1038-47.

16. Hergüner S, Kiliç G, Karakoç S, Tamay Z, Tüzün U, Güler N. Levels of depression, anxiety and behabioural problems and frquency of psychiatric disorder inchildren with chronic idiopatihic urticaria. $\mathrm{Br}$ ) Dermatol 2011;164:1342-47.

17. Engin B, Uguz F, Yilmaz E, Özdemir M, Mevlitoglu I. The levels of depression, anxiety and quality of life in patients with chronic idiopathic urticaria. J Eur Acad Dermatol Venereol 2008;22:36-40.

18. Tat TS. Higher Levels of Depression and Anxiety in Patients with Chronic Urticaria. Med Sci Monit 2019;25:115-20.

19. Ivarsson T, Svalander P, Litlere O. The Children's Depression Inventory (CDI) as measure of depression in Swedish adolescents. A normative study. Nord I Psychiatry 2006;60:220-6.

20. Weller K, Koti I, Makris M, Maurer M. Anxiety and depression seem less common in patients with autoreactive chronic spontaneous urticaria. Clin Exp Dermatol 2013;38:870-3. 